\title{
Using the Analytical Network Process to Select the Best Strategy for Reducing Risks in a Supply Chain
}

\author{
L. Hosseini, ${ }^{1}$ R. Tavakkoli-Moghaddam, ${ }^{2}$ B. Vahdani, ${ }^{2}$ S. M. Mousavi, ${ }^{2}$ and R. Kia ${ }^{1}$ \\ ${ }^{1}$ Department of Industrial Engineering, Firoozkooh Branch, Islamic Azad University, P.O. Box 148, Firoozkooh, Iran \\ ${ }^{2}$ Department of Industrial Engineering, College of Engineering, University of Tehran, P.O. Box 11155-4563, Tehran, Iran \\ Correspondence should be addressed to R. Tavakkoli-Moghaddam; tavakoli@ut.ac.ir
}

Received 26 November 2012; Revised 19 February 2013; Accepted 12 March 2013

Academic Editor: Gulfem Tuzkaya

Copyright (c) 2013 L. Hosseini et al. This is an open access article distributed under the Creative Commons Attribution License, which permits unrestricted use, distribution, and reproduction in any medium, provided the original work is properly cited.

\begin{abstract}
This paper considers four types of the most prominent risks in the supply chain. Their subcriteria and relations between them and within the network are also considered. In a supply chain, risks are mostly created by fluctuations. The aim of this study is to adopt a strategy for eliminating or reducing risks in a supply chain network. Having various solutions helps the supply chain to be resilient. Therefore, five alternatives are considered, namely, total quality management (TQM), leanness, alignment, adaptability, and agility. This paper develops a new network of supply chain risks by considering the interactions between risks. Perhaps, the network elements have interacted with some or all of the factors (clusters) or subfactors. We constitute supply chain risks in the analytic network process (ANP), which attracted less attention in the previous studies. Most of the studies about making a decision in supply chains have been applied in analytic hierarchy process (AHP) network. The present study considers the ANP as a well-known multicriteria decision making (MCDM) technique to choose the best alternative, because of the interdependency and feedbacks of different levels of the network. Finally, the ANP selects TQM as the best alternative among the considered ones.
\end{abstract}

\section{Introduction}

Supply chain risk has various derivations including process, control, demand, supply, and environmental supply, chain management (SCM). Lavaster et al. [1] proposed an experimental study in 50 various French companies for 142 common managers and supply chain managers. At the end, the term of chief scheme assigning assets exhibits a desirable cooperation with a business partner within a firm and between various collaborations of the similar chain. In some studies, adaptability and agility are identified as some elements in order to manage the supply chain risk [2].

Thun and Hoenig [3] explained two strategies encountering supply chain risk, namely, reactive and preventive supply chain risk management. The literature review shows that preventive strategies are applied more than reactive strategies. Furthermore, Tang and Tomlin [4] implemented the benefits of preventive strategies including reduction stocks, reactivity, diminution of the cost, and adding of the flexibility. Gurnani et al. [5] modeled the procurement problem as a Nash game by considering the buyer who has to allot its purchases from an expensive but reliable supplier and a cheaper but unreliable supplier. It was shown that the supplier selection decision depends on the reliability and the cost differentials between two suppliers.

Medina et al. [6] displayed an optimization method that considers the cost and the risk in order to promote the present condition. While selecting a decision variable, an initial objective function including the investment and the accidents' cost is developed. Consequently, the cost will be low in a favorable condition. In fact, the most important constraint is the fact that risk should not surpass the tolerated threshold level.

Nagurney et al. [7] developed a supply chain network model in order to allocate physical and electronic businesses. The formulation consisted of the risk in both supply and demand side. The aim was to achieve the maximum profit and minimize the risks by considering products and distributors 
as decision makers in an optimal multicriteria behavior model. Yu et al. [8] displayed the difficulty of sourcing decision in supply chain disruption. When demand is pricesensitive and the market size increases, supply disruption happens. The market switched within a supply disruption. They studied the condition in which global suppliers and household sellers applied for purchasing nonstrategic products. Hristidis et al. [9] surveyed prevalent awareness in organizing and examining the information in disaster conditions. They combined their achievements with computer science training: data integration and ingestion, data extraction, data repossession, data filtering, data mining, and decision support.

Sipahi and Timor [10] presented a review on recently published papers on group decision-making methods including the analytic hierarchy process (AHP) and analytic network process (ANP). Ergu et al. [11] suggested a simple model considering the matrix multiplication, vector dot product, and the explanation of consistent pairwise comparison matrix to change the pairwise. Schoenherr et al. [12] applied the AHP method in a case study considering 17 risk factors and allocating a special value to each factor. They illustrated the suitable alternative as a solution to reduce risk in a supply chain.

Agarwal et al. [13] presented the ANP to explore the relationship among lead time, cost, quality, and service level in a supply chain to select one strategy among a lean, agile or leagile (i.e., combining lean and, agile) supply chain. Saaty and Sodenkamp [14] purposed a mathematical model of the ANP considering benefit, opportunities, cost, and risk. Lee et al. [15] applied the ANP as a method to display the interaction between technologies, as a case study on telecommunication technologies. Yang and Tzeng [16] combined the decision making trial, evaluation laboratory, and a novel cluster weighted with the ANP methodology. Two separate case studies about applying the ANP in the SWOT analysis were displayed as follows [17]. One of them demonstrated a case study of applying the ANP in the SWOT system. Another one was a case study about the fuzzy ANP methodology to analyze the SWOT factors in the Turkish airline industry. The ANP methodology was used to consider potential dependencies among 4 factors [18]. Although most of the studies implemented in the context of supply chain risks have employed AHP, it should be confessed that risk is a complicated factor and its clusters and subfactors have implicit effects on each other.

Although, recently, the field of risk and supply chain received increased attentions by the researchers separately, the focus of this paper is to establish a combination of supply chain risks and the ANP network. We developed a new supply chain network considering the interdependency among risks (clusters). In this paper, we choose the ANP method because of its ability of representing the potential interactions, interdependences, and feedbacks among the supply chain risk elements. The supply chain risks in the ANP network have been employed in the present study in a new way. The mentioned risks in the network have appeared in most of supply chains. In particular, disruption risk has been introduced as one of the most influential risks in supply chain. Three remainder risks are known as intrinsic risks, which are associated with all the supply chains. These risks involved cost, time, and revenue [4]. The triple-A strategy (e.g., alignment, adaptability, and agility) mentioned as an alternative was considered as a basic combination for controlling supply chain risk. The alternative elements of the network have been displayed as two aspects, namely, reactive and preventive approaches.

The remainder of this paper is as follows. Section 2 explains the ANP methodology. Section 3 describes the ANP implementation and its steps in supply chain risks. Section 4 concludes the paper.

\section{Proposed ANP Methodology}

Although many studies about risk and its evaluation have been applied in the AHP, considering supply chain risks needs to have a method beyond the hierarchical relations. The hierarchy network can demonstrate the linear top-down connections and is feeble to display the dominance or subordinance and direct or indirect complex relationship. Since applying the AHP to illustrate the supply chain is limited, we are going to apply the ANP method in supply chain risk, because it considers risks and the feedbacks as well as the relationship among them. The ANP method can identify the intangible interdependencies and feedbacks between factors, subfactors, and alternatives. Perhaps, some elements of a cluster affect one or all the elements of other clusters. The reasons for applying ANP methodology are as follows: (1) selecting a strategy for supply chain risks reduction or elimination is a multicriteria decision problem, (2) being dependent on network elements, in which every element affects another factor, and (3) achieving the relative importance of some criteria and measures by simple weighting method is difficult [13].

The advantage of using the ANP in a supply chain is to indicate the impact of risks on each other, in which each of the risks can interact with other clusters (i.e., risks) and their subfactors. In addition, subfactors of each risk can influence other factors. The ANP methodology needs to apply a pairwise comparison matrix. This complicated and sensitive pairwise comparison would be performed by a skilled expert team. Viewpoints of some experts about pairwise comparison are presented in this paper and the mean of this collation is calculated regarding their opinions.

Our supply risks consist of supply quality, supply cost risk, and supply commitment. Process risk consists of time, quality, and capacity risk. Demand risk just depends on demand uncertainty [4]. Disruption risk is considered based on two main branches, namely, technological and natural disasters. Natural disasters are events, such as earthquake, hurricanes, flood, and volcano. Typical technological disasters are terrorism, nuclear power, plant emergencies, and hazardous materials [9]. In a today's business environment, the fluctuation of many companies has been derived from disruption risk and its subfactors. In other words, natural disaster and technological disaster are causes of survival or 
destruction of companies. Because of the mentioned reasons, disruption risk is highlighted in this paper.

The ANP can be applied to find the best strategy. In this paper, some alternatives are adopted in order to reduce or eliminate risk factors in a supply chain. These alternatives include total quality management (TQM), alignment, adaptability, agility, and lean. The AHP/ANP reduces a multidimensional problem into one-dimensional problem [14]. As the same as the AHP, in the ANP the main logic is based on pairwise comparison; however, this pairwise comparison matrix in the ANP is more complicated than that in the AHP. In the ANP, we should consider the relation between factors/subfactors and the connection between subfactors in one cluster to subfactors in another cluster in order to complete the super matrix. At first, the purpose is to find a strategy in order to decrease or eliminate the risk in the supply chain. Then pairwise comparison between network elements should be done, which is different from the AHP network comparison. To find the matrix priority and compute the consistency ratio (CR), we apply the Expert Choice software.

The ANP is the extended form of the AHP that considers many item feedbacks, the impact of every element on the other criteria, and independency between and within the levels. Generally, the ANP excogitates network relationship, whereas the AHP ignores interdependency. Steps for applying the ANP methodology are mentioned as below $[17,19]$.

Step 1. Illustrate the importance value of factors, based on four elements (i.e., supply risk, process risk, demand risk, and disruption risk). The pairwise comparison considers the impact of each element on others. There is a common method between AHP and ANP for pairwise comparison and priority vectors.

Step 2. Illustrating the magnitude of subfactors consisting of nine items (e.g., supply quality, supply cost risk, time risk, and capacity risk) should be done as the second stage. For comparing the elements in each cluster, scales in discrete interval $\{1-9\}$ are chosen [20]. Scale 9 shows the absolute significance of an element in comparison with others and scale 1 shows the equal significance of the elements, in which $a_{i j}$ indicates the importance of the $i$ th element with respect to the $j$ the element [19].

Step 3. Calculating the super matrix that is partitioned based on the cluster (factors) and its elements is derived from pairwise comparison. The super matrix consisting of $N$ clusters is presented as follows.

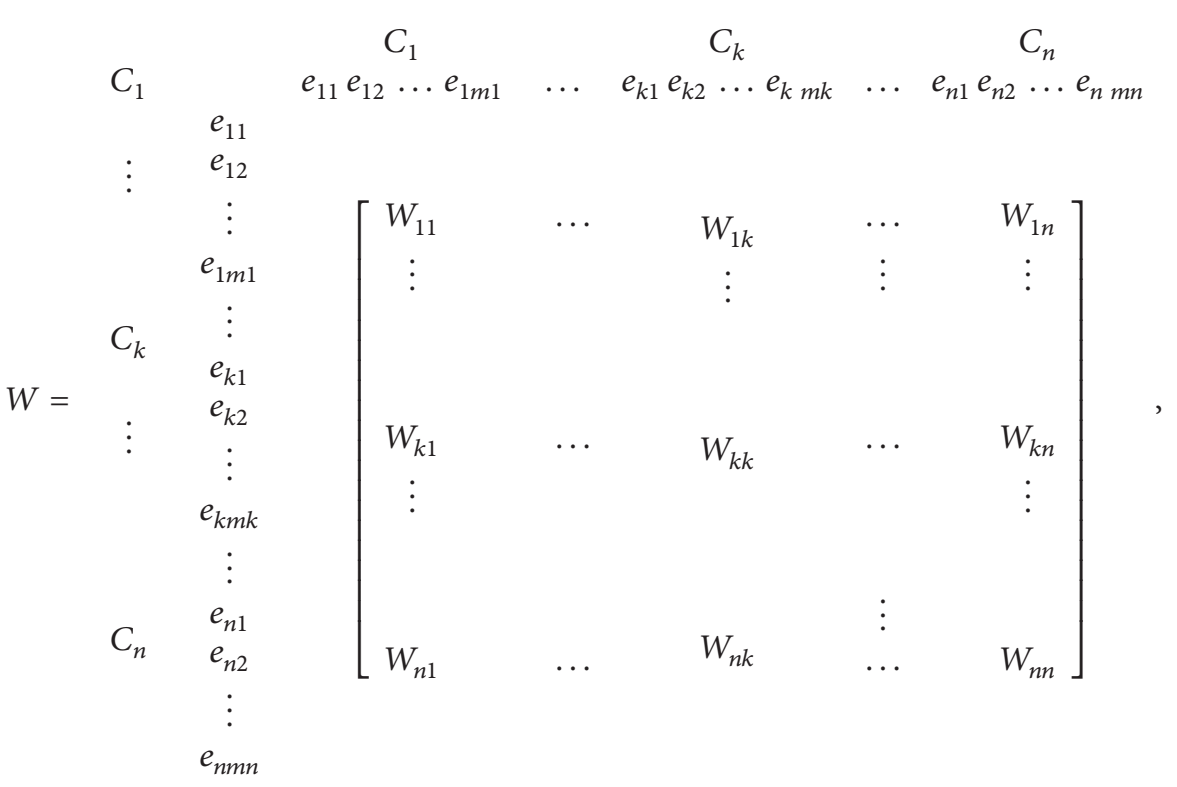

where $C_{k}$ is the $k$ th cluster $(k=1,2, \ldots, n)$ and each cluster $K$ consists of $m_{K}$ items displayed by $e_{k 1}, e_{k 2}, \ldots, e_{k m_{k}}$. Each column of $W_{i j}$ is the priority vector acquired from the identical pairwise comparison, indicating the significance of the elements in the $i$ th cluster with respect to an element in the $j$ th cluster [19].

Step 4. Computing the weighting of the super matrix via multiplying this matrix by priority of factors should be done as the final stage. Then, the limited super matrix is obtained by raising a weighted super matrix to powers. Consequently, we have some constant numbers to find one alternative as a solution.

\section{Application of the ANP Methodology in Supply Chain Risks}

The ANP methodology consists of three main steps, namely, (1) pairwise comparisons and local priority vectors, (2) weighted super matrix, and (3) super matrix formation 


\section{SR PR DR1 DR2}

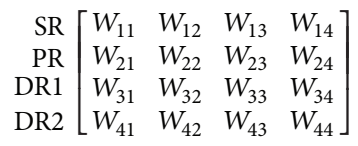

FIGURE 1: Construction of supply chain risks super matrix.

and transformation. Initial matrices represent the pairwise comparisons, which identify the priorities. These priorities corresponding to subfactors of pairwise comparison form the segments of the super matrix. The weighted super matrix will be changed to the limited super matrix by exponentiation. Produced numbers from the limited super matrix should be multiplied by priority of alternatives. The resulted numbers conduct us to find the best alternative with the highest score as the best strategy.

3.1. Pairwise Comparisons and Local Priority Vectors. The pairwise comparison is essential to start the ANP method. As a result, to find the cluster weights, comparing the subfactors is mandatory. It is also required to answer the question like how much supply quality (sub-factor) is more important than supply cost risk (sub-factor).

Constructing the super matrix has been done with respect to priority. These priorities are derived from pairwise comparison matrices. The super matrix consists of some elements, named as $W_{i j}$, in which each of these $W_{i j}$ is derived from pairwise comparison and presents a matrix. The size of these matrices depends on the compared factors and subfactors. For example $W_{11}, W_{12}, W_{21}, W_{22}$ consist of three rows and three columns; whereas $W_{14}, W_{24}$ include three rows and two columns or $W_{43}$ contains two rows and one column. The construction of the super matrix is shown in Figure 1.

Interdependency between supply chains' risk factors is illustrated by analyzing the influence of each factor on the other factors. By applying the analysis of both interior and exterior conditions of the organization, the dependency between supply risk factors is displayed intuitively in Figure 2 .

There are brief explanations about key elements of the supply chain network. Supply risk is connected with a fluctuation of input or row material to an enterprise from those predicted. The process risk is known as the likelihood of loss innate in profession process. Demand risk is occurring when it is not correctly predicted; it leads to the inequality between real demand and supply capacity. Disruption risk is mentioned as two concepts; natural and man-made disasters (i.e., natural events or economic crises, war, and terrorist incidents). The TQM principles develop strategies for decreasing the possibility of events of a predictable disaster [4]. TQM is a management concept that includes long-term triumph through client gratification. All associations of an organization can be improved by the TQM, including the enhancing operations, materials, products and culture, in which they work. By adopting approaches employing TQM, it will be suitable for the firms to decrease the probability of the occurrence of definite unpleasant events [4]. In order to
TABLE 1: Inner dependence matrix of the supply chain factors with respect to "Supply risk."

\begin{tabular}{lcccc}
\hline & $\begin{array}{c}\text { Process } \\
\text { risk }\end{array}$ & $\begin{array}{c}\text { Demand } \\
\text { risk }\end{array}$ & $\begin{array}{c}\text { Disruption } \\
\text { risk }\end{array}$ & Priority \\
\hline Process risk & 1 & 2 & 4 & 0.571 \\
Demand risk & & 1 & 2 & 0.286 \\
Disruption risk & & & 1 & 0.143 \\
\hline $\mathrm{CR}=0$. & & & &
\end{tabular}

decrease the negative impacts of certain unpleasant events related to supply, process, and demand risks, one can develop "triple-A-" based principles: alignment, adaptability, and agility that note long, medium, and shortterm viewpoints [2]. These strategies are displayed as follows. Aligning attentions through supply chain associations can decrease supply chain risks. For instance, to diminish the supply risk costs, the second supplier is considered. Another way to mitigate supply chain risks is being adaptive to market activities and supply chain agility allows a firm to reduce the effects of shortterm modifications in a demand or supply [4]. Agility in a supply chain can help a firm to be resilient in front of shortterm changes in demand or supply. Lean is about doing more with less. Maximizing the customer value while minimizing squander happened is the main idea of the lean approach. Clearly, lean means bringing more values for customers with fewer resources. A lean organization learns how to improve customer values and pays attention to its significant processes to improve them continuously. Lean concepts are applied when demand is stable and predictable and, as a result, diversification is low. Consequently, under those conditions where demand is inconstant and the variety of customer demand is high, a much higher level of agility is required. Leanness may be a factor of agility in certain status, but it will not qualify the organization to satisfy the exact needs of the customers more quickly [13].

Based on interdependencies displayed in Figure 1, the pairwise comparison matrices are computed for the factors as illustrated in Table 1. Tables 1, 2, 3, 4, and 5 show the results of calculating eigenvectors [17]. The consistency ratio (CR) are defined from consistency in the pairwise comparison matrices. Acceptable values for the CR is lower than 0.1; otherwise, we should change the comparison matrix according to the values proposed by the software.

3.2. Weighted Super Matrix. In the next stage, the interrelation matrices are used to compute the weighted super matrix. There are three different kinds of pairwise comparison for finding the weighted super matrix. Firstly, pairwise comparison based on the factor of supply chain risk to form the factor's priority is obtained in the previous part. Secondly, the pairwise comparison matrices are obtained with respect to one sub-factor among the other sub-factor of the same cluster [19]. They are mentioned in three comparisons for supply risk, three comparisons for process risk, and two comparisons for disruption risk. 


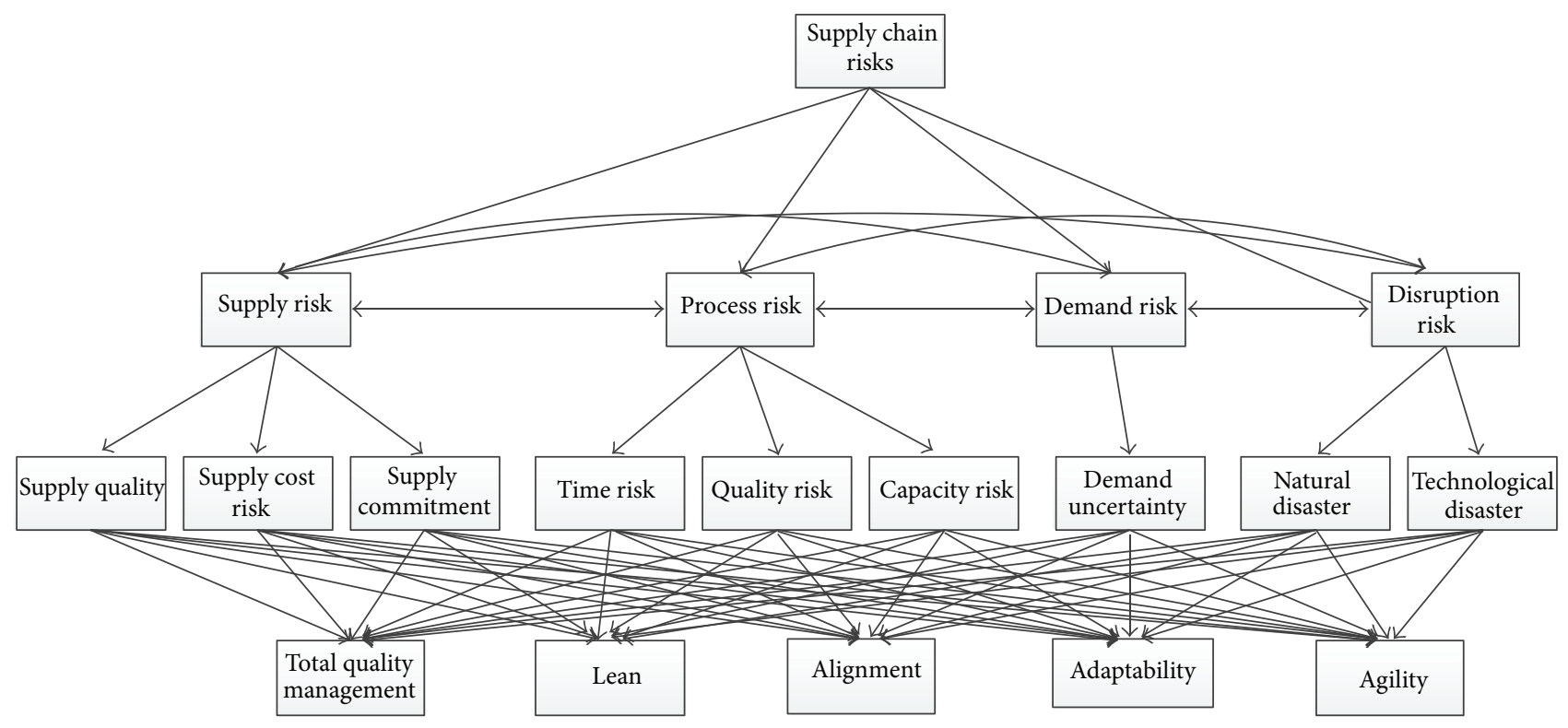

FIGURE 2: ANP network of risk factors in the supply chain.

TABLE 2: Inner dependence matrix of the supply chain factors with respect to "Process risk."

\begin{tabular}{lcccc}
\hline & Supply risk & $\begin{array}{c}\text { Demand } \\
\text { risk }\end{array}$ & $\begin{array}{c}\text { Disruption } \\
\text { risk }\end{array}$ & Priority \\
\hline Supply risk & 1 & 6 & 7 & 0.758 \\
Demand risk & & 1 & 2 & 0.151 \\
Disruption risk & & & 1 & 0.091 \\
\hline
\end{tabular}

$\mathrm{CR}=0.03$.

TABLE 3: Inner dependence matrix of the supply chain factors with respect to "Demand risk."

\begin{tabular}{lcccc}
\hline & Supply risk & $\begin{array}{c}\text { Process } \\
\text { risk }\end{array}$ & $\begin{array}{c}\text { Disruption } \\
\text { risk }\end{array}$ & Priority \\
\hline Supply risk & 1 & 1 & 4 & 0.415 \\
Process risk & & 1 & 7 & 0.5 \\
Disruption risk & & & 1 & 0.086 \\
\hline
\end{tabular}

$\mathrm{CR}=0.03$.

TABLE 4: Inner dependence matrix of the supply chain factors with respect to "Disruption risk."

\begin{tabular}{lcccc}
\hline & Supply risk & $\begin{array}{c}\text { Process } \\
\text { risk }\end{array}$ & $\begin{array}{c}\text { Demand } \\
\text { risk }\end{array}$ & Priority \\
\hline Supply risk & 1 & 4 & 3 & 0.63 \\
Process risk & & 1 & 2 & 0.218 \\
Demand risk & & & 1 & 0.151 \\
\hline
\end{tabular}

$\mathrm{CR}=0.1$.

Table 6 obtains the evaluated results of the priorities of supply risk factors based on supply quality subfactors,
TABLE 5: Inner dependence matrix of the supply chain risk factors.

\begin{tabular}{lcccc}
\hline & \multicolumn{3}{c}{ Supply chain factors } \\
& Supply risk & $\begin{array}{c}\text { Process } \\
\text { risk }\end{array}$ & $\begin{array}{c}\text { Demand } \\
\text { risk }\end{array}$ & $\begin{array}{c}\text { Disruption } \\
\text { risk }\end{array}$ \\
\hline Supply risk & 1 & 0.758 & 0.415 & 0.63 \\
Process risk & 0.571 & 1 & 0.5 & 0.218 \\
Demand risk & 0.286 & 0.151 & 1 & 0.151 \\
Disruption risk & 0.143 & 0.091 & 0.086 & 1 \\
\hline
\end{tabular}

which lead to find the first column of $W_{11}$. Two more pairwise comparisons, such as comparing supply risk based on supply cost risk and supply commitment, are required for completing the other columns of $W_{11}$ [19]. The segments of the super matrix in Table 9, including $W_{11}, W_{22}, W_{33}$, and $W_{44}$, are corresponded to comparisons with respect to a sub-factor among the same cluster. For example, for finding $W_{11}$ columns, three pairwise comparisons are conducted with respect to supply risk, subfactors in a supply risk cluster (e.g., supply quality, supply cost risk, and supply commitment). The scores of priority $(0.9,0.1)$ in Table 6 demonstrate the intensities of supply cost risk and supply commitment for the supply quality sub-factor in a supply risk cluster. Thirdly, the pairwise comparison matrix is acquired considering the subfactor of a factor among subfactors of the other factors, which affect the factor (i.e., all the elements in the supper matrix except $W_{11}, W_{22}, W_{33}$, and $\left.W_{44}\right)$. The first column of $W_{12}$ is driven from comparing supply risk sub-factor with time risk. The results are shown in Table 7 . The priority scores $(0.4$, $0.524,0.076)$ in Table 7 constituted the first column of $W_{12}$. The second column of $W_{12}$ corresponds to Table 8 , with respect to quality risk among subfactors of the supply risk. The priority scores $(0.436,0.481,0.05)$ in Table 8 constituted 
TABLE 6: Pairwise comparison matrix with respect to supply quality among the subfactors of supply risk.

\begin{tabular}{lccc}
\hline & \multicolumn{3}{c}{ Supply risk-supply quality } \\
& Supply cost risk & $\begin{array}{c}\text { Supply } \\
\text { commitment }\end{array}$ & Priority \\
\hline Supply cost risk & 1 & 9 & 0.9 \\
Supply commitment & & 1 & 0.1 \\
\hline
\end{tabular}

$\mathrm{CR}=0$.

the second column of $W_{12}$. The other remaining segments from the super matrix are calculated in same way.

3.3. Super Matrix Formation and Transformation. The super matrix is a frame segmented based on factors and subfactors. The associated results are shown in Table 9. The weighted super matrix is driven by multiplying a super matrix by cluster weights. For example, 0.571 is multiplied by nine elements of $W_{21}$. By multiplying 0.571 with the elements of the first column of $W_{21}$ (consisting of $0.14,0.333,0.528$ ), we obtain $0.0799,0.1901,0.3014$ as shown in the weighted super matrix. The weighted super matrix is displayed in Table 10. If the summation of each column for the weighted super matrix is not equal to one, the weighted super matrix needs to be modified to the normalized matrix. Table 11 consists of the changed elements. We used abbreviation of elements in the tables.

The summation of the columns of the super matrix in Table 10 demonstrated the scores more than one. Thus, this matrix must be modified, so that each column of the matrix should be equal to one [17]. This paper utilizes the estimated method to achieve the sum of the columns of the super matrix as one. In order to achieve the sum of the columns equaling one, the elements of a column should be summed, and then all of the elements should be divided by the summation. These calculations must be done for every column to acquire the normalized super matrix. For example, the sum of the first column of the super matrix is equal to 2, according to the mentioned method; every element of this column must be divided by 2 . As a result, the summation of the first column of the normalized super matrix is equal to one.

In the next stage, the limited super matrix can be calculated in order to select the best strategy. At the high powers of super matrix, convergent matrix can be found. In this study, the convergence matrix achieved at $W^{23}$, which is called as limited super matrix, is displayed in Table 12. In fact, nine fixed numbers should be earned. To select one strategy as a solution, it is required to multiply the alternative factors by these nine fixed numbers.

Table 13 demonstrates the alternatives' importance due to the risk factors, which is resulted from multiplying the limited super matrix by alternative pairwise comparison with respect to subfactors.

The columns of Table 13 correspond to pairwise comparison of alternative elements with respect to subfactors of risks. For instance, Table 14 constitutes the first column of Table 13. Other eight pairwise comparisons have to be implemented which are supply cost risk, supply commitment, time, quality,
TABLE 7: Pairwise comparison matrix with respect to time risk among the subfactors of supply risk.

\begin{tabular}{|c|c|c|c|c|}
\hline \multicolumn{5}{|c|}{ Supply risk-time risk } \\
\hline & $\begin{array}{l}\text { Supply } \\
\text { quality }\end{array}$ & $\begin{array}{l}\text { Supply } \\
\text { cost risk }\end{array}$ & $\begin{array}{c}\text { Supply } \\
\text { commitment }\end{array}$ & Priority \\
\hline Supply quality & 1 & 1 & 4 & 0.4 \\
\hline Supply cost risk & & 1 & 9 & 0.524 \\
\hline Supply commitment & & & 1 & 0.076 \\
\hline
\end{tabular}

TABLE 8: Pairwise comparison matrix with respect to quality risk among the subfactors of supply risk.

\begin{tabular}{lcccc}
\hline & \multicolumn{3}{c}{ Supply risk-quality risk } & \\
& $\begin{array}{c}\text { Supply } \\
\text { quality }\end{array}$ & $\begin{array}{c}\text { Supply } \\
\text { cost risk }\end{array}$ & $\begin{array}{c}\text { Supply } \\
\text { commitment }\end{array}$ & Priority \\
\hline Supply quality & 1 & 1 & 8 & 0.463 \\
Supply cost risk & & 1 & 9 & 0.481 \\
Supply commitment & & & 1 & 0.05 \\
\hline
\end{tabular}

$\mathrm{CR}=0$.

capacity risk, demand uncertainty, natural, and technological disaster. By multiplying the elements of matrices in Table 12 by Table 13, the alternative scores are found as shown in Table 15.

The highest numbers show more importance and effectiveness of alternatives. As a result, the highest derived number leads to selecting of the best possible alternative, which leads to reduce or eliminate the risk factors in a supply chain. The main goal of the ANP evaluation is to indicate the best reactive or preventive alternative. The final conclusion of weights for each solution, which is derived from multiplying Table 13 by the limited super matrix, displays the results in a descending order as shown in Table 15. The results identify that the TQM item with the highest score (i.e., 0.483) is selected as the best alternative for reduction of risk in a supply chain. Another priority ordering of the alternative strategies is lean, alignment, adaptability, and agility. When supply chains implement TQM, leanness, agility, adaptability, or alignment strategies, they lead to declining of the bullwhip effect and external disruptions resilience. TQM has significant importance in this ranking and the experts confirm the integrity of the results. It is mentioned as a comprehensive and structured approach in organizational management in the long term, which considers customer satisfaction. In the TQM approach, all parts of supply chain are associated with enhancing and upgrading processes, products, business, and the culture of their work.

\section{Conclusion}

There are numerous risks that can influence operation and revenue of a supply chain; however, four most important risks (i.e., supply risk, process risk, demand risk, and disruption risk) were considered in this paper. To cope with these 
TABLE 9: Super matrix formed from every subfactor risks.

\begin{tabular}{lcccccccccc}
\hline & & \multicolumn{3}{c}{ Supply risk } & \multicolumn{3}{c}{ Process risk } & \multicolumn{3}{c}{ Demand risk } \\
& & SQ & SCR & SC & TR & QR & CR & DU & ND & DI \\
\hline \multirow{3}{*}{ Supply risk } & SQ & 0 & 0.875 & 0.75 & 0.4 & 0.463 & 0.637 & 0.731 & 0.57 \\
& SCR & 0.9 & 0 & 0.25 & 0.524 & 0.481 & 0.258 & 0.188 & 0.34 & 0.236 \\
& SC & 0.1 & 0.125 & 0 & 0.76 & 0.056 & 0.105 & 0.081 & 0.08 & 0.082 \\
\hline \multirow{3}{*}{ Process risk } & TR & 0.14 & 0.54 & 0.333 & 0 & 0.75 & 0.5 & 0.528 & 0.68 & 0.701 \\
& QR & 0.333 & 0.297 & 0.333 & 0.75 & 0 & 0.5 & 0.333 & 0.2 & 0.243 \\
& CR & 0.528 & 0.163 & 0.333 & 0.25 & 0.25 & 0 & 0.14 & 0.11 & 0.056 \\
\hline Demand risk & DU & 1 & 1 & 1 & 1 & 1 & 1 & 0 & 1 \\
\hline \multirow{2}{*}{ Disruption risk } & ND & 0.111 & 0.176 & 0.25 & 0.25 & 0.125 & 0.899 & 0.75 & 0 & 1 \\
& TD & 0.889 & 0.833 & 0.75 & 0.75 & 0.875 & 0.111 & 0.25 & 1 \\
\hline
\end{tabular}

TABLE 10: Weighted super matrix based on supply chain risk factors.

\begin{tabular}{|c|c|c|c|c|c|c|c|c|c|c|}
\hline \multicolumn{11}{|c|}{ Weighted super matrix } \\
\hline & & \multicolumn{3}{|c|}{ Supply risk } & \multicolumn{3}{|c|}{ Process risk } & \multirow{2}{*}{$\begin{array}{c}\text { Demand risk } \\
\text { DU }\end{array}$} & \multicolumn{2}{|c|}{ Disruption risk } \\
\hline & & SQ & SCR & SC & TR & QR & $\mathrm{CR}$ & & ND & DI \\
\hline \multirow{3}{*}{ Supply risk } & SQ & 0 & 0.875 & 0.75 & 0.303 & 0.3509 & 0.4830 & 0.303 & 0.36 & 0.429 \\
\hline & SCR & 0.9 & 0 & 0.25 & 0.3971 & 0.3646 & 0.1955 & 0.078 & 0.22 & 0.148 \\
\hline & $\mathrm{SC}$ & 0.1 & 0.125 & 0 & 0.5760 & 0.0425 & 0.0796 & 0.034 & 0.05 & 0.050 \\
\hline \multirow{3}{*}{ Process risk } & TR & 0.0799 & 0.3083 & 0.1901 & 0 & 0.75 & 0.5 & 0.264 & 0.15 & 0.150 \\
\hline & QR & 0.1900 & 0.1695 & 0.1901 & 0.75 & 0 & 0.5 & 0.166 & 0.044 & 0.060 \\
\hline & $\mathrm{CR}$ & 0.3013 & 0.0931 & 0.1901 & 0.25 & 0.25 & 0 & 0.070 & 0.025 & 0.012 \\
\hline Demand risk & DU & 0.286 & 0.286 & 0.286 & 0.151 & 0.151 & 0.151 & 0 & 0.151 & 0.151 \\
\hline \multirow{2}{*}{ Disruption risk } & ND & 0.0158 & 0.0239 & 0.0357 & 0.0227 & 0.0114 & 0.0808 & 0.064 & 0 & 1 \\
\hline & $\mathrm{TD}$ & 0.1270 & 0.1191 & 0.1072 & 0.0682 & 0.0796 & 0.0101 & 0.021 & 1 & 0 \\
\hline
\end{tabular}

TABLE 11: Normalized weighted super matrix based on supply chain risk factors.

\begin{tabular}{|c|c|c|c|c|c|c|c|c|c|c|}
\hline \multicolumn{11}{|c|}{ Normalized weighted super matrix } \\
\hline & & \multicolumn{3}{|c|}{ Supply risk } & \multicolumn{3}{|c|}{ Process risk } & \multirow{2}{*}{$\begin{array}{c}\text { Demand risk } \\
\text { DU }\end{array}$} & \multicolumn{2}{|c|}{ Disruption risk } \\
\hline & & SQ & SCR & SC & TR & QR & $\mathrm{CR}$ & & ND & DI \\
\hline \multirow{3}{*}{ Supply risk } & SQ & 0 & 0.438 & 0.375 & 0.120 & 0.175 & 0.242 & 0.303 & 0.180 & 0.215 \\
\hline & SCR & 0.450 & 0 & 0.125 & 0.158 & 0.182 & 0.098 & 0.078 & 0.110 & 0.074 \\
\hline & SC & 0.050 & 0.062 & 0 & 0.229 & 0.021 & 0.040 & 0.034 & 0.025 & 0.026 \\
\hline \multirow{3}{*}{ Process risk } & TR & 0.040 & 0.154 & 0.095 & 0 & 0.375 & 0.250 & 0.264 & 0.075 & 0.076 \\
\hline & QR & 0.095 & 0.084 & 0.095 & 0.298 & 0 & 0.250 & 0.166 & 0.022 & 0.027 \\
\hline & CR & 0.150 & 0.046 & 0.095 & 0.099 & 0.125 & 0 & 0.070 & 0.013 & 0.006 \\
\hline Demand risk & DU & 0.143 & 0.143 & 0.143 & 0.060 & 0.076 & 0.075 & 0 & 0.075 & 0.076 \\
\hline \multirow{2}{*}{ Disruption risk } & ND & 0.008 & 0.013 & 0.018 & 0.009 & 0.006 & 0.040 & 0.064 & 0 & 0.500 \\
\hline & TD & 0.064 & 0.060 & 0.054 & 0.027 & 0.040 & 0.005 & 0.021 & 0.500 & 0 \\
\hline
\end{tabular}

risks, some strategies (e.g., reduction or prevention strategy) were adopted. To select one strategy, decision making techniques were applied. The ANP is applied to illustrate the significance of the supply chain risks factor and to evaluate the suitable solution. Selecting a strategy to handle risk in supply chain management is a multicriteria decision problem. Many factors and elements are relevant and have interactions in making a decision, using the ANP. Some of specifications, which were intrinsic, could be measured. In this way, a synthetic score was found out among easily weighted techniques. The ANP methodology could identify the suitable alternative based on the scores. With respect to the illustrative results, TQM with score of 0.483 was selected as reactive supply chain risk management. Future research can consider other various risks on a supply chain with their sub-factor to expand this network. Another suggestion 
TABLE 12: Limited super matrix based on supply chain risk factors.

\begin{tabular}{|c|c|c|c|c|c|c|c|c|c|c|}
\hline \multicolumn{11}{|c|}{ Limited super matrix } \\
\hline & & \multicolumn{3}{|c|}{ Supply risk } & \multicolumn{3}{|c|}{ Process risk } & \multirow{2}{*}{$\begin{array}{c}\text { Demand risk } \\
\text { DU }\end{array}$} & \multicolumn{2}{|c|}{ Disruption risk } \\
\hline & & SQ & SCR & SC & TR & QR & CR & & $\mathrm{ND}$ & DI \\
\hline \multirow{3}{*}{ Supply risk } & SQ & 0.2069 & 0.2069 & 0.2069 & 0.2069 & 0.2069 & 0.2069 & 0.2069 & 0.2069 & 0.2069 \\
\hline & SCR & 0.1725 & 0.1725 & 0.1725 & 0.1725 & 0.1725 & 0.1725 & 0.1725 & 0.1725 & 0.1725 \\
\hline & $\mathrm{SC}$ & 0.0655 & 0.0655 & 0.0655 & 0.0655 & 0.0655 & 0.0655 & 0.0655 & 0.0655 & 0.0655 \\
\hline \multirow{3}{*}{ Process risk } & $\mathrm{TR}$ & 0.1413 & 0.1413 & 0.1413 & 0.1413 & 0.1413 & 0.1413 & 0.1413 & 0.1413 & 0.1413 \\
\hline & $\mathrm{QR}$ & 0.1221 & 0.1221 & 0.1221 & 0.1221 & 0.1221 & 0.1221 & 0.1221 & 0.1221 & 0.1221 \\
\hline & CR & 0.0826 & 0.0826 & 0.0826 & 0.0826 & 0.0826 & 0.0826 & 0.0826 & 0.0826 & 0.0826 \\
\hline Demand risk & $\mathrm{DU}$ & 0.0963 & 0.0963 & 0.0963 & 0.0963 & 0.0963 & 0.0963 & 0.0963 & 0.0963 & 0.0963 \\
\hline \multirow{2}{*}{ Disruption risk } & ND & 0.0477 & 0.0477 & 0.0477 & 0.0477 & 0.0477 & 0.0477 & 0.0477 & 0.0477 & 0.0477 \\
\hline & TD & 0.0623 & 0.0623 & 0.0623 & 0.0623 & 0.0623 & 0.0623 & 0.0623 & 0.0623 & 0.0623 \\
\hline
\end{tabular}

TABLE 13: Alternatives' weights based on subfactor risks (over criteria).

\begin{tabular}{lccccccccc}
\hline & & \multicolumn{3}{c}{ Over criteria } & & & DU & ND & TD \\
\hline Alternatives & SQ & SCR & SC & TR & QR & CR & 0.481 & 0.340 & 0.519 \\
Lean & 0.484 & 0.553 & 0.497 & 0.477 & 0.529 & 0.481 & 0.389 \\
Alignment & 0.298 & 0.218 & 0.281 & 0.287 & 0.211 & 0.282 & 0.356 & 0.218 & 0.19 \\
Adaptability & 0.102 & 0.147 & 0.134 & 0.155 & 0.181 & 0.156 & 0.227 & 0.191 & 0.345 \\
Agility & 0.085 & 0.051 & 0.048 & 0.044 & 0.049 & 0.044 & 0.040 & 0.038 & 0.040 \\
\hline
\end{tabular}

TABLE 14: Priority of five alternatives based on supply quality.

\begin{tabular}{|c|c|c|c|c|c|c|}
\hline & TQM & Lean & Alignment & Adaptability & Agility & Priority \\
\hline TQM & 1 & 3 & 5 & 5 & 9 & 0.485 \\
\hline Lean & & 1 & 4 & 6 & 7 & 0.271 \\
\hline Alignment & & & 1 & 1 & 6 & 0.166 \\
\hline Adaptability & & & & 1 & 4 & 0.055 \\
\hline Agility & & & & & 1 & 0.23 \\
\hline
\end{tabular}

$\mathrm{CR}=0$.

TABLE 15: Final weight of alternatives to find the best strategy.

\begin{tabular}{lc}
\hline Alternative & Weights \\
\hline Total quality management & 0.483 \\
Lean & 0.264 \\
Alignment & 0.165 \\
Adaptability & 0.054 \\
Agility & 0.034 \\
\hline
\end{tabular}

is to consider other risks, such as political/social risks and behavioral risks. Furthermore, focus on other alternatives for omitting or reducing risks can be exposed in a more completed network.

\section{References}

[1] O. Lavaster, A. Gunasekaran, and A. Splanzani, "Supply chain risk management in French companies," Decision Support Systems, vol. 52, no. 4, pp. 828-838, 2012.
[2] H. L. Lee, "The triple-A supply chain," Harvard Business Review, vol. 82, no. 10, pp. 102-112, 2004.

[3] J. H. Thun and D. Hoenig, "An empirical analysis of supply chain risk management in the German automotive industry," International Journal of Production Economics, vol. 131, no. 1, pp. 242-249, 2011.

[4] C. Tang and B. Tomlin, "The power of flexibility for mitigating supply chain risks," International Journal of Production Economics, vol. 116, no. 1, pp. 12-27, 2008.

[5] H. Gurnani, M. Gumus, S. Ray, and T. Ray, "Optimal procurement strategy under supply risk," Asia-Pacific Journal of Operational Research, vol. 29, no. 1, pp. 1-6, 2012.

[6] H. Medina, J. Arnaldos, and J. Casal, "Process design optimization and risk analysis," Journal of Loss Prevention in the Process Industries, vol. 22, no. 5, pp. 566-573, 2009.

[7] A. Nagurney, J. Cruz, J. Dong, and D. Zhang, "Supply chain networks, electronic commerce, and supply side and demand side risk," European Journal of Operational Research, vol. 164, no. 1, pp. 120-142, 2005.

[8] H. Yu, A. Z. Zeng, and L. Zhao, "Single or dual sourcing: decision-making in the presence of supply chain disruption risks," Omega, vol. 37, no. 4, pp. 788-800, 2009.

[9] V. Hristidis, S. C. Chen, T. Li, S. Luis, and Y. Deng, "Survey of data management and analysis in disaster situations," Journal of Systems and Software, vol. 83, no. 10, pp. 1701-1714, 2010.

[10] S. Sipahi and M. Timor, "The analytic hierarchy process and analytic network process: an overview of applications," Management Decision, vol. 48, no. 5, pp. 775-808, 2010.

[11] D. Ergu, G. Kou, Y. Peng, and Y. Shi, "A simple method to improve the consistency ratio of the pair-wise comparison matrix in ANP," European Journal of Operational Research, vol. 213, no. 1, pp. 246-259, 2011. 
[12] T. Schoenherr, V. M. Rao Tummala, and T. P. Harrison, "Assessing supply chain risks with the analytic hierarchy process: Providing decision support for the offshoring decision by a US manufacturing company," Journal of Purchasing and Supply Management, vol. 14, no. 2, pp. 100-111, 2008.

[13] A. Agarwal, R. Shankar, and M. K. Tiwari, "Modeling the metrics of lean, agile and leagile supply chain: an ANP-based approach," European Journal of Operational Research, vol. 173, no. 1, pp. 211-225, 2006.

[14] T. L. Saaty and M. Sodenkamp, "Making decision in hierarchic and network system," Journal of Applied Decision Sciences, vol. 1, no. 1, pp. 24-79, 2008.

[15] H. Lee, C. Kim, H. Cho, and Y. Park, "An ANP-based technology network for identification of core technologies: a case of telecommunication technologies," Expert Systems with Applications, vol. 36, no. 1, pp. 894-908, 2009.

[16] J. L. Yang and G. H. Tzeng, "An integrated MCDM technique combined with DEMATEL for a novel cluster-weighted with ANP method," Expert Systems with Applications, vol. 38, no. 3, pp. 1417-1424, 2011.

[17] I. Yüksel and M. Dağdeviren, "Using the analytic network process (ANP) in a SWOT analysis: a case study for a textile firm," Information Sciences, vol. 177, no. 16, pp. 3364-3382, 2007.

[18] M. Sevkli, A. Oztekin, O. Uysal, G. Torlak, A. Turkyilmaz, and D. Delen, "Development of a fuzzy ANP based SWOT analysis for the airline industry in Turkey," Expert Systems With Application, vol. 39, no. 1, pp. 14-24, 2012.

[19] H. Lee, "An analytic network process approach to operationalization of five force model," Applied Mathematical Modeling, vol. 36, no. 4, pp. 1783-1795, 2012.

[20] T. L. Saaty, The Analytic Hierarchy Process, McGraw-Hill, New York, NY, USA, 1980. 

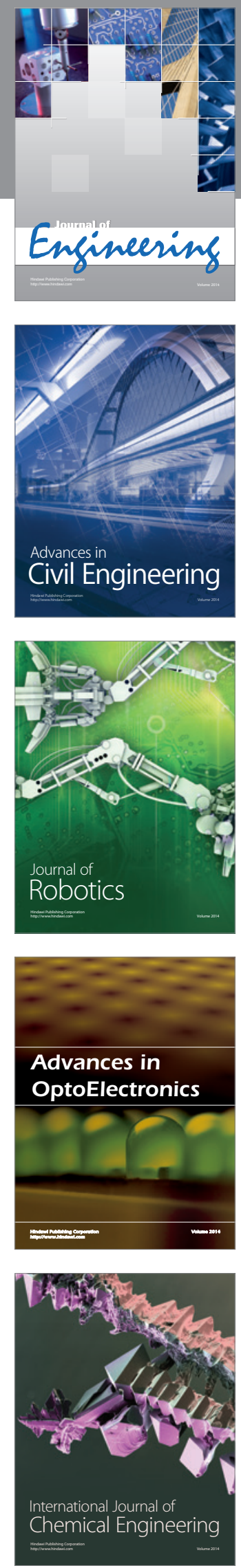

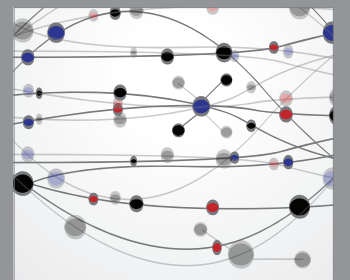

The Scientific World Journal
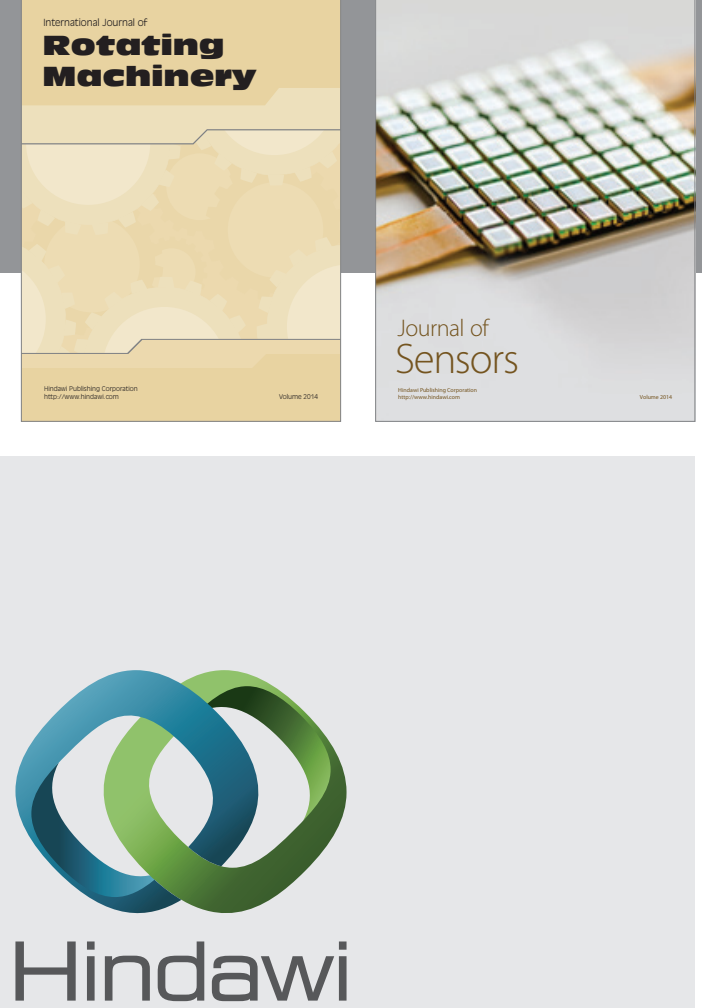

Submit your manuscripts at http://www.hindawi.com
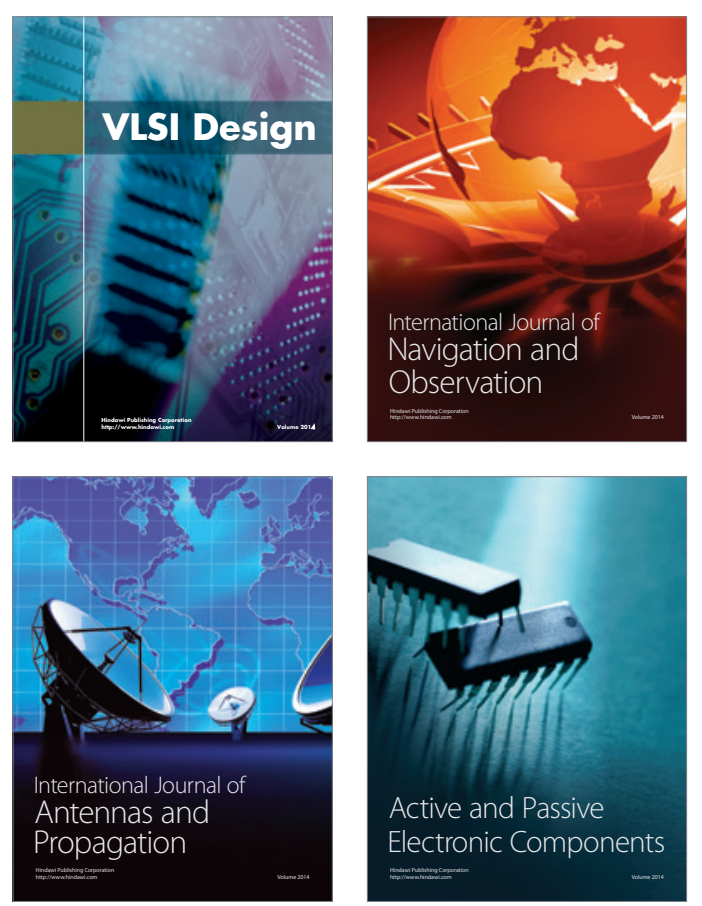
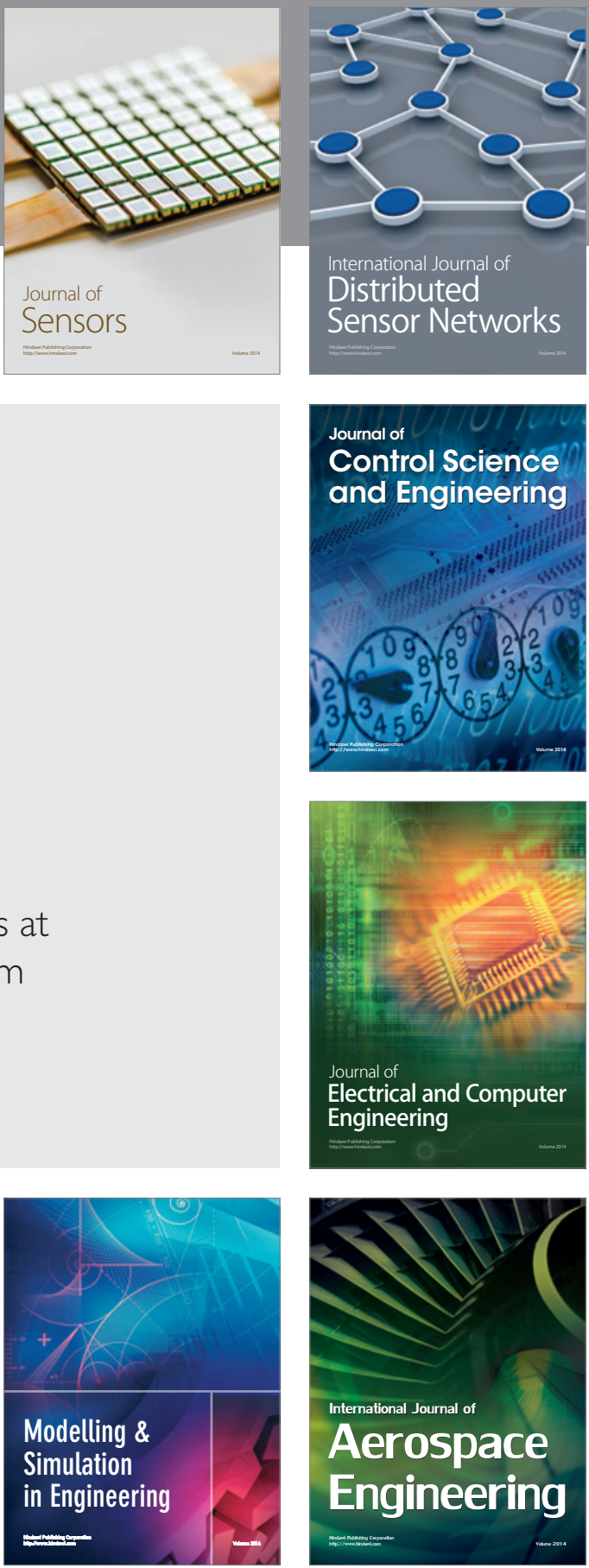

Journal of

Control Science

and Engineering
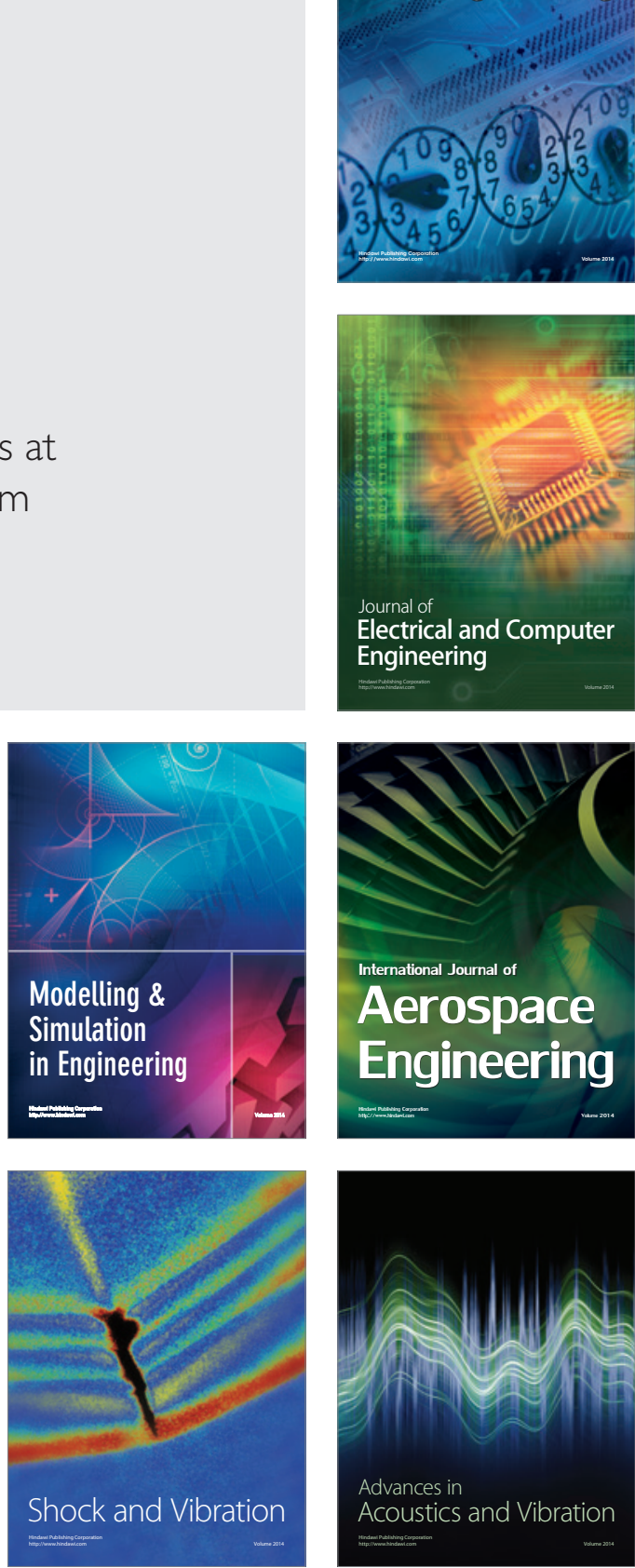